\title{
Glucose-Fatty Acid Interaction in Skeletal Muscle and Adipose Tissue in Insulin Resistance
}

\author{
M. CAHOVÁ, H. VAVŘíNKOVÁ, L. KAZDOVÁ \\ Institute for Clinical and Experimental Medicine, Prague, Czech Republic
}

Received October 12, 2005

Accepted January 13, 2006

On-line available February 23, 2006

\begin{abstract}
Summary
Insulin resistance (IR) is the result of long-lasting positive energy balance and the imbalance between the uptake of energy rich substrates (glucose, lipids) and energy output. The defects in the metabolism of glucose in IR and type 2 diabetes are closely associated with the disturbances in the metabolism of lipids. In this review, we have summarized the evidence indicating that one of the important mechanisms underlying the development of IR is the impaired ability of skeletal muscle to oxidize fatty acids as a consequence of elevated glucose oxidation in the situation of hyperglycemia and hyperinsulinemia and the impaired ability to switch easily between glucose and fat oxidation in response to homeostatic signals. The decreased fat oxidation results into the accumulation of intermediates of fatty acid metabolism that are supposed to interfere with the insulin signaling cascade and in consequence negatively influence the glucose utilization. Pathologically elevated fatty acid concentration in serum is now accepted as an important risk factor leading to IR. Adipose tissue plays a crucial role in the regulation of fatty acid homeostasis. The adipose tissue may be the primary site where the early metabolic disturbances leading to the development of IR take place and the development of IR in other tissues follows. In this review we present recent evidence of mutual interaction between skeletal muscle and adipose tissue in the establishment of IR and type 2 diabetes.
\end{abstract}

Key words

Insulin resistance $\bullet$ Fatty acid $\bullet$ Adipose tissue $\bullet$ Skeletal muscle $\bullet$ Glucose-fatty acid cycle

\section{Introduction}

Insulin resistance is generally taken to mean a reduced ability of insulin to stimulate glucose transport and utilization. This metabolic abnormality, associated with dyslipidemia, hypertension and hyperinsulinemia, is characteristic for the "Insulin Resistance Syndrome" and often leads to the development of type 2 diabetes. The mechanisms underlying the development of insulin resistance are undoubtedly numerous. There is growing body of evidence indicating that net positive energy balance and disordered fat storage and mobilization are central factors in the pathogenesis of this metabolic disorder (Lewis et al. 2002). Beside this, insulin resistance may be induced by other metabolic disorders, i.e. imbalance of several hormones like catecholamines 
(Reaven 1996), glucocorticoids (Ward et al. 2003) or growth hormone (Rizza et al. 1982, Hansen et al. 1986). Mutation of some members of insulin signaling cascade (insulin receptor, insulin receptor-substrate) also leads to the manifestation of insulin resistance. Nevertheless, such mutation constitutes a very rare cause of type 2 diabetes (Kahn 1998).

Estimation of whole-body insulin sensitivity and action with euglycemic clamp technique is mainly a reflection of the glucose disposal by the muscles (60-70\%) (DeFronzo et al. 1992) while adipose tissue only accounts for about $10 \%$ of whole-body insulinstimulated glucose uptake (Smith 2002). This fact has led to the extrapolation that whole body insulin resistance not only occurs in muscles, but also starts there. Nevertheless, the high correlation between disturbances in normal metabolism of adipose tissue (obesity, lipodystrophy) and the manifestation of insulin resistance indicates the important role of adipose tissue in its etiology (Kahn and Flier 2000). Recent findings have shown that insulin resistance and impaired insulin action occur early in adipose tissue (in fact, long before glucose intolerance develops) and adipose tissue is now recognized as the primary site of its origin (Hotamisligil 2000). Over the last decade a large number of factors with diverse functions secreted by adipose tissue has been identified and adipose tissue is now considered to be an endocrine organ (Ahima and Flier 2000). These factors include a variety of proteins termed adipocytokines either with insulin sensitizing effect (adiponectin, leptin) or promoting insulin resistance ( $\mathrm{TNF} \alpha$, resistin etc), that act in an autocrine, paracrine or endocrine fashion to control various metabolic functions (Pittas et al. 2004). The detailed listing is beyond the scope of this review (for review see Mattison and Jensen 2003, Fasshauer and Paschke 2003). Adipose tissue has traditionally been considered an energy storage organ that accumulates the excess of energy in the form of triglycerides and releases it in the form of FFA during energy shortage. FFA serve not only as highly energetic fuel but also as important signaling molecules and their availability is an important factor influencing glucose utilization in muscles.

These findings suggest that altered lipid metabolism might directly contribute to the onset of insulin resistance, particularly in the muscle and liver, leading to compensatory hyperinsulinemia which is believed to exacerbate the condition. In this review we will concentrate on the role of free fatty acids in the pathogenesis of insulin resistance.

\section{The association of elevated FFA serum levels and the development of insulin resistance}

Fatty acids are an important source of energy for many tissues, including skeletal muscle, which is the main site of the manifestation of insulin resistance. On the other hand, as surfactants they are toxic substances and even when bound to protein carrier their elevated concentration in the serum is considered to be one of the important risk factors for the development of insulin resistance and type 2 diabetes (Shafrir and Raz 2003). The elevated free fatty acid (FFA) serum levels were demonstrated in the serum of subjects at high risk of type 2 diabetes (obesity, lipodystrophy, autonomous nervous system dysfunction) or in some experimental models of insulin resistance induced by diet manipulation (highsucrose feeding). The acute elevation of fatty acid levels in healthy volunteers, which can be generated by intralipid/heparin infusion, can also result in whole body and muscle insulin resistance. According to very short half-life of FFA in the serum (about $2 \mathrm{~min}$ ) it is possible to expect that FFA are quickly internalized and their increased intracellular availability may lead to changes in metabolism of glucose at the level of substrate competition, enzyme regulation, intracellular signaling and/or gene transcription that account for the insulin resistance seen in states such as metabolic syndrome and type 2 diabetes (Kraegen et al. 2001).

\section{Free fatty acids and glucose uptake in muscle}

The first evidence that cardiac and skeletal muscles possess mechanisms that allow these tissues to shift readily back and forth between carbohydrate and fat as oxidative energy sources depending primarily on the availability of FFA was obtained by Randle et al. (1963). Based on their original experiments showing that the increased availability of FFAs decreased carbohydrate uptake and increase glucoso-6-phosphate in isolated perfused rat heart and hemidiaphragm Randle and colleagues formulated a theory that became known as glucose-fatty acid cycle or Randle cycle. The key points of this model were: increased availability of FFAs in the circulation produces an increase in intramuscular acetylCoA and citrate content, which results in the inhibition of pyruvate dehydrogenase and phophofructokinase, and this in turn reduces glucose oxidation and glycolysis. Subsequent increase in intracellular glucose-6-phosphate concentration would inhibit hexokinase II activity, which 
would result into an increase of intracellular glucose concentration and a decrease of muscle glucose uptake.

Originally, the glucose-fatty acid cycle was developed to explain the abnormalities in carbohydrate metabolism via higher fatty acid availability associated with diabetes mellitus, starvation and carbohydrate deprivation. Later, when it was found that insulin resistance is almost always associated with obesity and type 2 diabetes and these metabolic states are also characterized by elevated levels of free fatty acids (Schalch and Kipnis 1965), the concept of glucose-fatty acid cycle was extended to insulin-resistant states. The effort of many investigators was concentrated on the question whether increased fat oxidation could be responsible for the development of insulin resistance and type 2 diabetes.

The development of the method of euglycemichyperinsulinemic clamping brought the possibility to study how several hour infusion of intralipid/heparin in healthy volunteers leading to the elevation of systemic FFAs alters insulin-stimulated glucose metabolism. More recently the glucose fatty acid interactions were reexamined using whole body indirect calorimetry (to determine oxidative and non-oxidative glucose utilization) in combination with hyperinsulinemic clamping (to determine insulin sensitivity). Some of the groups showed that raising plasma FFA concentrations increased fat oxidation and inhibited both carbohydrate oxidation and glucose uptake, as would be predicted by the glucose fatty acid cycle (Thiebaud et al.1982, Felley et al. 1989). In contrast, other groups found an inhibitory effect of fatty acids on glucose oxidation but not on glucose uptake (Bevilacqua et al. 1987, Bonadonna 1989). The explanation of this apparent contradiction was provided in the study of Boden et al. (1991) who reported that in healthy volunteers the fatty acid-mediated inhibition of insulin- stimulated glucose uptake develop only after $4 \mathrm{~h}$ of fat infusion. Thus insufficient time of lipid plus insulin infusion $(2 \mathrm{~h})$ was the most likely reason why the inhibitory effect of fatty acids on glucose uptake was not found in some studies (Boden 1997). Boden et al. (1991) also showed that lipid infusion produced insulin resistance in glucose disposal only several hours after it had already decreased glucose oxidation which suggested that the glucose fatty acid cycle might not be responsible for insulin resistance. In accordance with this are the results of Kelley et al. (1993) who found that lipid infusion produced a decrease of insulin-stimulated glucose oxidation, but there was a greater decrease in glycogen synthesis. This result would not have been predicted by the mechanism used to explain the glucose-fatty acid cycle.

The NMR spectroscopy opened a new methodological approach. The group of Shulman (2000) used ${ }^{13} \mathrm{C}$ and ${ }^{31} \mathrm{P}$ NMR spectroscopy to measure muscle glycogen content and glucose-6-phosphate concentration in leg muscle of healthy subjects who were maintained under euglycemic hyperinsulinemic conditions with either low $(0.2 \mathrm{mmol} / \mathrm{l})$ or high $(2 \mathrm{mmol} / \mathrm{l})$ plasma fatty acid levels (Roden et al. 1996). Increasing of plasma fatty acid concentration to about $2 \mathrm{mmol} / \mathrm{l}$ for $5 \mathrm{~h}$ caused a reduction of approximately $50 \%$ in insulin stimulated rates of leg muscle glycogen synthesis and the similar reduction of whole body glucose oxidation together with a decrease in intracellular glucoso-6-phosphate concentration compared to controls maintained at low plasma FFA levels. In contrast to the changes predicted by Randle cycle, which would expect that fat-induced insulin resistance would result in an increase of intramuscular glucoso-6-phosphate, Shulman and coworkers found that the drop in muscle glycogen synthesis was preceded by a fall in intramuscular glucoso-6-phosphate. These data suggest that increases in plasma fatty acid concentration initially induce insulin resistance by inhibiting glucose transport (indicated by glucoso-6-phosphate concentration) and that the reduction in muscle glycogen synthesis and glucose oxidation follows (Shulman 2000). The reduction in insulin-activated glucose transport and phosphorylation activity in normal subjects reached under experimental condition (i.e. by maintenance of healthy volunteers at high plasma fatty acid levels by intralipid/heparin infusion) is similar to that seen in obese individuals (Petersen et al. 1998), patients with type 2 diabetes (Rothman et al. 1992) and lean normoglycemic insulinresistant offspring of type 2 diabetic individuals (Rothman et al. 1995).

\section{Glucose-fatty acid cycle in reverse}

Since the introduction of "glucose-fatty acid cycle" concept several investigators focused their attention on the reverse process, i.e. on the effect of glucose availability and oxidation on fatty acid oxidation. Several studies showed that when glucose availability increases, the fat oxidation decreases (Wolfe and Peters 1987, Wolfe et al. 1988). The experimental design employed in these experiments did not exclude a 
possibility that this response is mediated, at least in part, by insulin-induced inhibition of lipolysis, resulting in the decreased fatty acid availability. However, Sidossis et al. (1996) showed that infusion of glucose plus insulin decreases plasma fatty acid oxidation and increases carbohydrate oxidation even when fatty acid availability is maintained constant by infusion of exogenous lipids. This finding suggests that accelerated carbohydrate oxidation directly inhibits fatty acid oxidation by mechanism other than inhibition of lipolysis.

The results of Kelley and Mandarino (1990) who found, using leg balance technique, that glucose oxidation was increased in leg muscle of type 2 diabetic subjects studied postabsortively under the conditions of fasting hyperglycemia were consistent with these findings. Furthermore, when hyperglycemia was reduced to normal levels by insulin infusion designed to suppress hepatic glucose output in subjects with type 2 diabetes, leg glucose oxidation decreased and fat oxidation increased. The increased glucose oxidation in skeletal muscle was found in obese insulin-resistant rats (Torgan et al. 1990, Cortez et al. 1991) and in skeletal muscle of insulinresistant non-obese hereditary hypertriglyceridemic (HHTg) rats incubated in vitro in the presence of $1 \mathrm{mmol} / 1$ palmitate (Cahová et al. 2004a,b). The alterations in fatty acid metabolism in insulin-resistant muscle were demonstrated also during fasting. Blaak et $a l$. (2000) demonstrated, using forearm balance technique and indirect calorimetry, that FFA uptake and oxidation in muscle are impaired in the forearm muscles of type 2 diabetic subjects during fasting and after isoproterenol stimulation. The failure to augment lipid oxidation during fasting conditions may be one of the mechanisms leading to the accumulation of lipid metabolism intermediates which may in turn contribute to the disturbances in glucose metabolism seen in insulin resistance.

\section{Metabolic inflexibility of fatty acid utilization in insulin resistance}

In lean, healthy individuals, skeletal muscle displays substantial metabolic flexibility, with the capacity to switch from predominantly lipid oxidation and high rates of fatty acid uptake during fasting conditions (Andres et al. 1956) to the suppression of lipid oxidation and increased glucose uptake, oxidation and storage under insulin-stimulated conditions (Kelley et al. 1990). Ukropcova et al. (2005) found that the capacity of skeletal muscle to oxidize fat under appropriate conditions is related to leanness, aerobic fitness and insulin sensitivity. It has been proposed that the impaired ability to increase the dependence upon fat oxidation is related to the pathogenesis of insulin resistance in skeletal muscle (Kelley and Mandarino 2000, Storlien et al. 2004). In order to evaluate whether impaired muscle capacity to increase fat oxidation is related to the pathogenesis of insulin resistance, it is necessary to explain apparently contradictory observation described above that insulin resistance in muscle can be induced by elevated plasma fatty acid levels. On the other hand, there is also a convincing set of evidence that insulin-resistant skeletal muscle can manifest reduced efficiency of fat oxidation during fasting metabolism despite elevated levels of plasma FFA (Blaak et al. 2000). Kelley and Mandarino (2000) described the concept of "metabolic inflexibility" as one of the characteristic features of insulin-resistant skeletal muscle. Metabolically healthy skeletal muscle is characterized by the ability to switch easily between glucose and fat oxidation in response to homeostatic signals. The skeletal muscle of individuals with type 2 diabetes and obesity shows a great reduction of metabolic flexibility. This includes the lower reliance on fat and a greater reliance on glucose oxidation during fasting and lower stimulation of glucose oxidation and impaired suppression of fat oxidation by insulin (Kelley 2005).

\section{The malonyl-CoA as a fuel sensing and signaling mechanism}

One possible mechanism that explains the diminished oxidation of fatty acids during hyperglycemia and hyperinsulinemia is based on the role of malonyl$\mathrm{CoA}$ as a link between fuel metabolism and signal transduction in skeletal muscle. The predominant function of malonyl-CoA in skeletal muscle is probably allosteric inhibition of the activity of carnitine palmitoyl transferase I (CPT I). CPT I is essential enzyme enabling the FFA entry into mitochondria and thus their oxidation. The intracellular concentration of malonyl-CoA in muscle is acutely (in minutes) regulated according to the metabolic state of the cell. In early studies McGarry et al. (1983) showed that the concentration of malonyl CoA in skeletal muscle is diminished by $80 \%$ after $48 \mathrm{~h}$ starvation, in keeping with the increased need for fatty acid oxidation in the fasting state. Saha et al. (1995) showed that the concentration of malonyl-CoA increased several times in rat soleus muscle when incubated in the 
presence of glucose and insulin within 20 min and within $6 \mathrm{~h}$ when the muscle was inactivated by denervation (i.e. in the situations when the need for fatty acid oxidation is decreased). The rapid response of malonyl-CoA concentration to changes in fuel supply or energy expenditure of the muscle cells has been referred to as the malonyl-CoA fuel sensing and signaling mechanism (Ruderman et al. 1999).

The existence of malonyl-CoA fuel sensing and signaling mechanism in humans is suggested by the observation of Bavenholm et al. (1998) that the concentration of malonyl-CoA increased in human leg muscle during an euglycemic hyperinsulinemic clamp and whole body fatty acid oxidation was markedly diminished in evaluated subjects. In the above mentioned study Sidossis et al. (1996) reported that decreases in fatty acid oxidation in humans undergoing concomitantly euglygemic-hyperinsulinemic clamp and intralipid infusion are accompanied by the decrease in the oxidation of long-chain fatty acylcarnitine in muscle suggesting inhibition of CPT I. The authors explain their findings by the increase of malonyl-CoA concentration in the situation of accelerated glucose metabolism.

A number of findings suggest an association between sustained elevations in the concentration of malonylCoA and insulin resistance in skeletal muscle. The high levels of malonyl-CoA were found in muscle of several animal models of insulin resistance (hyperglycemic and/or hyperinsulinemic) including the fa/fa rat (Saha et al. 1997), KKA ${ }^{y}$ mouse (Saha et al. 1994) and rats infused with glucose for 1-4 days (Laybutt et al. 1997). The increased levels of malonyl-CoA were also proved in rat muscle in which the insulin resistance was induced by denervation (Saha et al. 1994). On the other hand, the only increase of intracellular concentration of malonyl CoA is not sufficient explanation for the development of insulin resistance. The elevation of intracellular malonyl CoA was not proved in models of high-fat diet induced insulin resistance (Ruderman et al. 1999).

\section{Fatty acid metabolites and insulin action in muscle}

As discussed in previous sections, there is growing body of evidence that the increased oxidation of fatty acids is not the primary cause of insulin resistance. On the contrary, the perturbations in lipid metabolism that result in accumulation of intracellular fatty acid metabolites in muscle cell, either through increased delivery or decreased metabolism, induce insulin resistance. The first step in the metabolism of fatty acids in any tissue is the activation of the fatty acid to its long chain acyl coenzyme A (LC-AcCoA) derivative. Then LC-AcCoAs can be transported into the mitochondria via the action CPT I and oxidized in the beta-oxidation pathway. Alternatively, the LC-AcCoAs may be esterified to mono- and diglycerides and stored as triglycerides or incorporated into phospholipids in membranes (Faergeman and Knudsen 1997). The concentration of LC-AcCoAs in muscle is increased by fasting (Carroll et al. 1983), decreased by insulin (Oakes et al. 1997a,b) and is therefore an indicator of the extent of lipid metabolism in a tissue (Kraegen et al. 2001).

The common feature of various situations leading to the development of insulin resistance is the increased cytosolic concentration of LC-AcCoAs, which may represent a link between fatty acid metabolites and insulin action in muscle. LC-AcCoA levels are increased in muscle from fat-fed insulin-resistant rats and their concentration was not significantly reduced by $2 \mathrm{~h}$ insulin infusion during hyperinsulinemic euglycemic clamp (Oakes et al. 1997a). Another study (Oakes et al. 1997b) showed that insulin resistance was ameliorated by diet or exercise and that this effect was closely related to the ability of insulin to suppress the intracellular LC-AcCoA content. Insulin resistance generated by chronic infusion of glucose is accompanied by accumulation of LC-AcCoAs in muscle (Saha et al. 1995). The LC-AcCoA levels are elevated in muscle of rats fed high sucrose diet for two weeks (Cahová et al., unpublished results). Based on these findings we can conclude that intracellular LC-AcCoA content increases as the result of various mechanisms all of them leading to the development of insulin resistance. The intracellular LC-AcCoA content may increase as the consequence of their increased availability in circulation (e.g. after highfat diet) or as the consequence of an increased glucose supply followed by the rise of intracellular malonyl-CoA content and the inhibition of fatty acid entry into the mitochondria. It has been hypothesized that the elevated intracellular LC-AcCoA levels negatively influence the metabolism of glucose, but their precise role has not yet been fully elucidated. LC-AcCoA as a signaling molecule may influence a variety of cellular processes and may act via different mechanisms. Thompson and Cooney (2000) showed that LC-AcCoA inhibited the activity of hexokinase isolated from rat and human soleus muscle 
in vitro. Hexokinase is the first enzyme of intracellular glucose metabolism and its inhibition may significantly reduce the glucose transport into the cell.

Another possible target of LC-AcCoA represents protein kinase $\mathrm{C}$ the role of which in the insulin signaling is now extensively studied. According to this hypothesis the increased content of intracellular fatty acid metabolites (like LC-AcCoA but also diacylglycerol or ceramides) activates a serine/threonine kinase cascade possibly initiated by protein kinase theta. This series of events leads to the phosphorylation of serine/threonine sites on insulin receptor substrates. Serinephosphorylated forms of these proteins fail to activate PI 3-kinase, resulting in decreased activation of glucose transport and other downstream events. If this hypothesis is correct, any perturbations that lead to the accumulation of fatty acid metabolites might be expected to result in insulin resistance (Shulman 2000, Hegarty et al. 2003).

Chicco et al. (1999) investigated the mutual dependence of the development of insulin resistance and the content of intracellular LC-AcCoA and triglycerides during long-term ( 30 weeks) feeding of high sucrose diet in Wistar rats. The content of LC-AcCoA increased after the first three weeks of high sucrose feeding in gastrocnemius muscle, but this rise was not accompanied by any changes in the activity of pyruvate dehydrogenase or glycogen synthase measured in the same tissue. The glucose infusion rate measured during hyperinsulinemiceuglycemic clamp was at this time slightly, but significantly decreased. The increased amount of LC-AcCoA in the muscle cells was in this experiment rather an early indicator of the disturbances of lipid metabolism than the direct cause leading to the impairment of insulin sensitivity. Thompson and Cooney (2000) showed during the in vitro experiments that the glucose uptake in soleus muscle is decreased after four hours incubation in the presence of various fatty acids and that this decrease correlates with the intracellular LC-AcCoA content. In contrast, no correlation between LC-AcCoA content and the glycogen synthesis was found in this study. Therefore, it is likely that lipids regulate glycogen synthesis and glucose transport via different mechanisms. Similar results were also obtained by our group. The two weeks of high sucrose feeding led to a significant increase in the LC-AcCoA and triglyceride content in soleus muscle, but had no effect on glycogen synthesis in vitro. Interestingly, the glycogen synthesis was significantly decreased after the addition of palmitate into incubation medium (Cahová et al., unpublished results). In the study of Poynten et al. (2003) two weeks of administration of nicotinic acid induced insulin resistance in humans manifested as the lowering of glucose infusion rate during euglycemic hyperinsulinemic clamp. Induction of insulin resistance with nicotinic acid was related to elevated circulating fatty acids, decreased fat oxidation and decreased nonoxidative glucose disposal but not to increased intramuscular lipid content or LC-AcCoA content.

Interesting results challenging the "lipotoxic" model of skeletal muscle insulin resistance were reported by Perdomo et al. (2004). Their studies demonstrated that overexpression of CPT I in L6 myotubules increases the rate of fatty acid oxidation and enhances insulin stimulation of glucose disposal. When the cells were preincubated with palmitate, CPT I overexpression ameliorated the negative effects of fatty acids on insulinstimulated glycogen synthesis, glucose uptake and phosphorylation of protein kinase B. These effects of CPT I overexpression were independent of changes in intracellular triacylglycerol, diacylglycerol, ceramide, or LC-AcCoA content. These data suggest that at this model the beneficial effect of $\beta$-oxidation on insulin sensitivity was mediated by a mechanism independent of lipid accumulation.

Taken together, these data indicate that the role of LC-AcCoA and other intermediates of lipid metabolism in the pathophysiology of insulin resistance have not yet been fully elucidated and further experimental work is needed. The potential interactions between glucose and lipid metabolism in skeletal muscle in insulin resistance are summarized in Figure 1.

\section{The role of adipose tissue in the development of insulin resistance}

The skeletal muscle is the main tissue responsible for the insulin-stimulated glucose disposal and it was also considered to be the most important site where pathological mechanisms leading to the development of insulin resistance originate. Nevertheless, there is strong evidence from animal models indicating that this extrapolation is not fully justified. As reported by Abel et al. (2001) the animals with adipose-specific GLUT4 gene deletion developed whole body insulin resistance what implicated the important role of the adipose tissue for whole-body glucose disposal. Another interesting finding in the animal models is that muscle GLUT4 depletion is associated with a marked increase in 


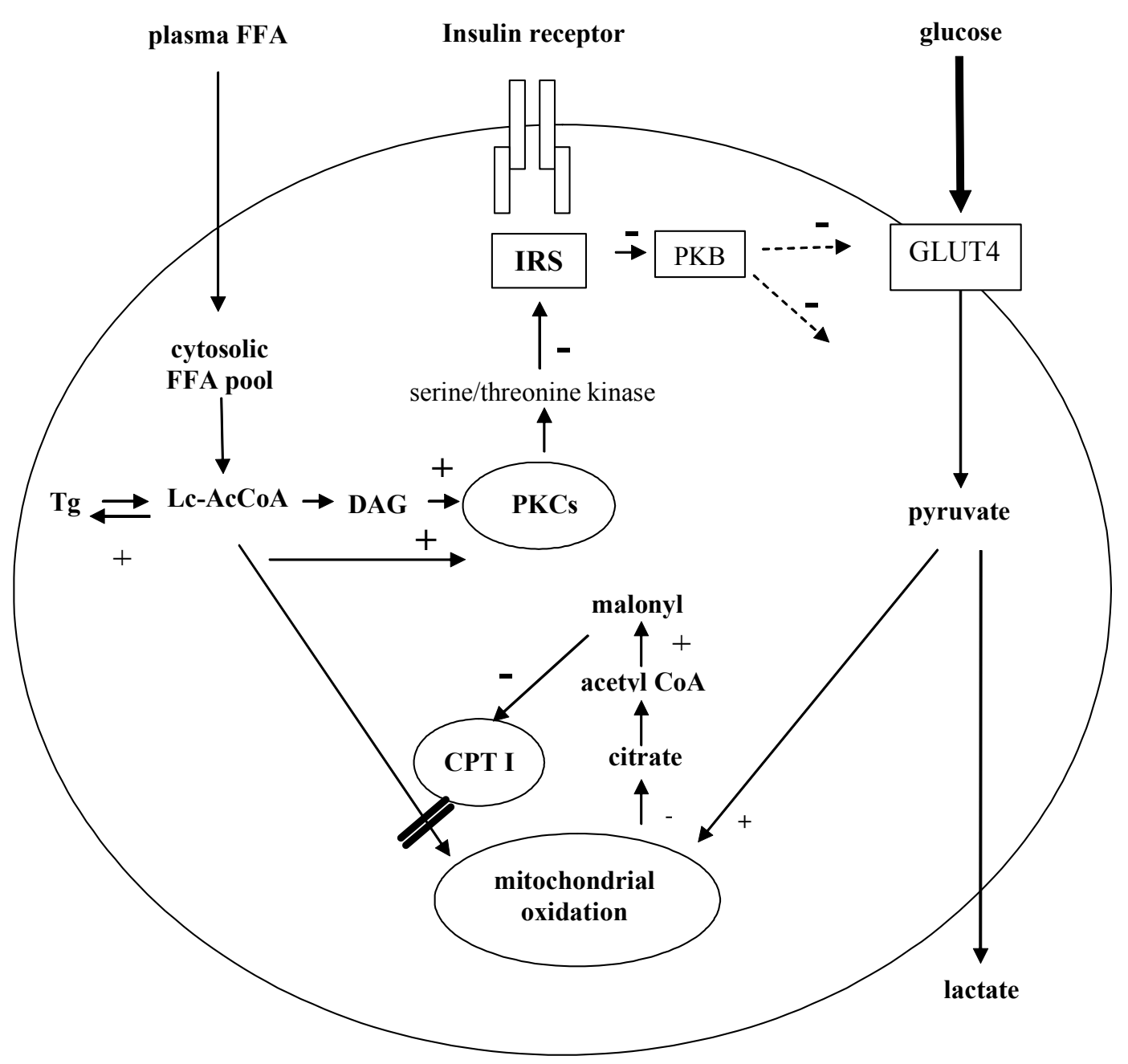

Fig. 1. Potential interactions between lipid and glucose metabolism in skeletal muscle in insulin resistance. When glucose for oxidation is present in excess of immediate needs of the cell, the mitochondrial and subsequently cytosolic concentration of citrate increases. Citrate serve as a source of cytosolic acetyl CoA which is conversed by carboxylation to malonyl CoA. Malonyl CoA inhibits CPT I and prevents further entry of LC-ACCOA into mitochondria for oxidation what results in their accumulation in the cytosol. The lipid metabolism intermediates may activate PKC and further members of serine/threonine kinase cascade leading to phosphorylation of serine and threonine sites on insulin receptor and insulin receptor substrates. Serine phosphorylated forms of these proteins fail to activate downstream members of insulin signaling cascade, resulting in decreased activation of glucose transport and other downstream events (e.g. glycogen synthesis). + potential activators, - potential inhibitors.

glucose uptake by the fat and with the expanded adipose tissue mass (Kim et al. 2000). This cross-talk between tissues supports the possibility that insulin resistance may be initiated in one tissue and followed by a series of events in other tissues (Smith 2002).

The impaired tyrosine phosphorylation of IRS-1 associated with approx. $50 \%$ reduction in PI-3 kinase activity was identified in skeletal muscle of diabetic and insulin-resistant subjects. The insulin-stimulated translocation of GLUT4 transporter is impaired in skeletal muscle of type 2 diabetic subjects (Zierath et al. 1996), but the total GLUT4 protein content and mRNA specific expression was not different from normal muscle cells (Garvey et al. 1992). As the consequence, insulin- stimulated glucose transport is reduced in skeletal muscle from type 2 diabetic subjects. Interestingly, the recent in vitro experiments showed that this phenomenon is reversible in skeletal muscle. In the above mentioned work of Abel et al. (2001) muscles from insulin-resistant mouse restored normal insulin responsiveness after several hours of incubation in medium with normal glucose concentration $(5 \mathrm{mmol} / \mathrm{l})$. Similarly, Zierath et al. (1994) reported that preincubation of the human diabetic muscle strips for two hours at a physiological glucose concentration normalizes the insulin response and on the contrary, preincubation of the tissue biopsies from normal subjects for only $2 \mathrm{~h}$ at high glucose concentration impairs the effect of insulin. 
The situation is quite different in adipose tissue. Adipocytes from type 2 diabetic subjects also have a marked reduction in the insulin-stimulated IRS-1 phosphorylation, which is mainly due to $70 \%$ reduction in IRS-1 protein expression (Rondinone et al. 1997). Both PI-3 kinase activation and the downstream activation of $\mathrm{PKB} / \mathrm{Akt}$ are significantly impaired in adipocytes from type 2 diabetics (Carvalho et al. 2000). In contrast to muscle cells, preincubation of the human fat cells for $16 \mathrm{~h}$ in physiological $(5.6 \mathrm{mmol} / \mathrm{l})$ or high (16.8 and $25 \mathrm{mmol} / \mathrm{l})$ glucose concentration does not impair the acute insulin stimulatory effect on glucose uptake nor does preincubation of diabetic adipocytes at a physiological glucose concentration restore the acute insulin response after $6 \mathrm{~h}$ (Smith 2002). In contrast to skeletal muscle a marked reduction of both GLUT4 mRNA and protein was found in adipocytes (Rondinone et al. 1997).

All these data indicate that there are basic differences in insulin signaling and protein and gene expression between two major insulin-sensitive tissues. It can be speculated that the adipose tissue may initiate and/or be the initial target organ for insulin where insulin resistance develops. This could than lead to a series of events (such as increased FFA or various adipocytokine production) whereby insulin resistance is induced or augmented in muscle and liver (Smith 2002).

\section{The role of adipose tissue in the regulation of FFA serum concentration}

Adipose tissue is a major reservoir of energy stored as triglycerides which can be quickly released in the form of fatty acids. The net effect of lipolysis (i.e. production of fatty acids) depends on the whole complex of processes on the lipid droplet surface. The hydrolysis of stored triglycerides is regulated primarily by hormones like catecholamines via cAMP-dependent protein kinases. Nevertheless, recent results indicate the existence of additional regulatory mechanisms. Perilipins coat the lipid droplets of adipocytes and are thought to have an important role in the regulation of triglyceride hydrolysis. Perilipins are believed to inhibit the actions of lipases on intracellular lipids perhaps by acting as barriers to lipase access. Upon catecholamine stimulation, perilipins are hyperphosphorylated by protein kinase $\mathrm{A}$ and this phosphorylation has been suggested to facilitate lipase access to the lipid droplets (Londos et al. 2005). The perilipin knockout mouse exhibits reduced adipose tissue mass, elevated basal lipolysis and impaired catecholamine-stimulated lipolysis. These animals also show increased tendency to develop glucose intolerance and peripheral insulin resistance (Tansey et al. 2001). Another important factor determining the intensity of lipolysis is the effectivity of removing of released fatty acids from the reactive center of hormone-sensitive lipase that depends predominantly on the capacity of fatty acid transporter proteins. The amount of fatty acids finally released into the circulation is determined by the reesterification of released fatty acids, i.e. on the availability of glucose.

Another important function of adipose tissue is its role in buffering the fatty acid fluxes both in postprandial period and during fasting. If this buffering function is impaired, then other tissues like liver and muscle are exposed to excessive fluxes of lipid fuels which may lead to the impairment of normal regulation mechanisms (Frayn 1998). Unlike the situation in any other tissue, fatty acid movement across the adipocyte membrane is bidirectional.

\section{The role of adipose tissue in postprandial phase}

In the postprandial state hormone sensitive lipase (HSL) is suppressed and the pathway of fatty acid esterification is stimulated, the FFAs released by lipoprotein lipase (LPL) from VLDL and chylomicrons are "trapped" in the form of triglycerides in adipose tissue. From this point of view, adipose tissue is a dynamic tissue with a very active pattern of metabolism. It plays a crucial role in buffering the flux of fatty acids in the circulation in the postprandial period (Frayn 2002). The rate of fatty acid uptake and esterification is highly controlled. It is stimulated by insulin, as was demonstrated both in vivo (Frayn et al. 1994) and in vitro (Dyck et al. 2001). In recent years another regulator of this pathway has been identified - acylation-stimulating protein (ASP) secreted by adipocytes into circulation. It is produced by two-step process involving three proteins of the alternate complement system C3, factor B and adipsin, all of which are synthesized and secreted by adipocytes (Cianflone et al. 2003). Its production is stimulated by the presence of chylomicrons (Maslowska et al. 1997). As was recently shown ASP production in adipose tissue in vivo is temporally correlated with the uptake of fatty acids (Saleh et al. 1998). This protein may be involved in the entrapment of fatty acids released by 
Table 1. The effect of wortmannin on adrenaline- and methoxamine-stimulated lipolysis and glucose utilization in adipose tissue of high sucrose diet fed rats in vitro.

\begin{tabular}{|c|c|c|c|c|}
\hline & \multicolumn{2}{|c|}{ Lipolysis } & \multicolumn{2}{|c|}{ Glucose utilization } \\
\hline & $\begin{array}{l}\text { Glycerol } \\
(\mu \mathrm{mol} / \mathrm{g} \text { w.w. })\end{array}$ & $\begin{array}{l}\text { FFA } \\
(\mu \mathrm{mol} / \mathrm{g} \mathrm{w.w.})\end{array}$ & $\begin{array}{l}\text { Lactate production } \\
\mu \mathrm{mol} / \mathrm{g} \text { v.v. }\end{array}$ & $\begin{array}{l}\text { Incorporation into } \\
\text { lipids ( } \mu \mathrm{mol} / \mathrm{g} \text { w.w. })\end{array}$ \\
\hline Basal & $3.7 \pm 0.3$ & $1.6 \pm 0.07$ & $7.3 \pm 0.5$ & $1.5 \pm 0.2$ \\
\hline Basal + wortmannin & $3.2 \pm 0.5$ & $2.4 \pm 0.18^{*}$ & $3.1 \pm 0.3^{*}$ & $1.0 \pm 0.1$ \\
\hline Adrenaline & $11.8 \pm 2.2^{\#}$ & $9.1 \pm 1.5^{\#}$ & $6.1 \pm 0.7$ & $3.3 \pm 0.2^{\#}$ \\
\hline Adrenaline + wortmannin & $12.2 \pm 1.8$ & $18.6 \pm 2.6^{*}$ & $4.8 \pm 0.3^{*}$ & $1.8 \pm 0.15^{*}$ \\
\hline Methoxamine & $2.9 \pm 0.6$ & & $6.3 \pm 1.1$ & $1.9 \pm 0.1$ \\
\hline Methoxamine + wortmannin & $3.1 \pm 0.5$ & & $4.0 \pm 0.4^{*}$ & $1.1 \pm 0.05^{*}$ \\
\hline
\end{tabular}

Data are means \pm S.E.M., $n=8-10$ * Significant effect $(p<0.05)$ of wortmannin, ${ }^{*}$ significantly different $(p<0.05)$ from basal values.

LPL and their transport to the surface of adipocytes.

The necessary condition determining the effective buffering function of adipose tissue is rapid alterations in adipose tissue metabolism. The adipose tissue in lean individuals can switch from a negative to a positive FFA balance during the transition from fasting to the postprandial state. In insulin-resistant obese individuals the adipose tissue FFA balance remains negative postprandially (Frayn et al. 1996).

This observation is also supported by the results of our group comparing the response of isolated adipose tissue to previous glucose load in vivo. While the adipose tissue of normal rats increased the glucose uptake within $30 \mathrm{~min}$ after glucose load and transformed glucose into fatty acids through de novo fatty acid synthesis, the adipose tissue of non-obese HHTg rats did not respond to increased supply of glucose at all (Cahová et al. 2004a,b). There are many findings that several functions of adipose tissue necessary for effective buffering are impaired in insulin resistance. The impaired ability of insulin to suppress HSL has been repeatedly reported (Chen et al. 1987, Groop et al. 1989). Similarly, the ability of insulin to up-regulate LPL activity and hence triacylglycerol clearance is impaired in obesity, a frequent risk factor for type 2 diabetes (Ong and Kern 1989, Coppack et al. 1992). In vitro, the defect of the ability of adipose tissue to increase fatty acid uptake in coordination with their increasing concentration was found in non-obese animal model of insulin resistance - HHTg rats (Cahová et al. 2004a,b). The inefficient trapping of fatty acids in adipose tissue in the postprandial period leads to the inappropriately elevated FFA concentrations in the postprandial period accompanied by various pathological consequences resulting in the insulin resistance.

\section{The role of adipose tissue in fasting}

In the fasting, the main function of adipose tissue is to supply energy in the form of FFAs which are predominantly released from intracellular triglycerides by HSL. There is a large outward flow of FFAs from the cells to the circulation. Nevertheless, a continuous cycle of fatty acid release by hydrolysis of endogenous triglycerides and their reesterification occurs in the adipose tissue. The intensity of both processes depends on the acute metabolic needs of the organism. Adrenaline, besides stimulation of HSL, also stimulates glucose uptake into adipocytes. The positive effect of adrenaline on glucose uptake in adipose tissue was known since early sixties (Mosinger 1968), but the exact biological significance and mechanism were poorly understood. From this point of view there is a profound difference between the effect of adrenaline on skeletal muscle and adipose tissue as in muscle adrenaline strictly inhibits the glucose entry into the cell. The results of our group indicate that the glucose uptake and reesterification of released fatty acids after adrenaline stimulation is impaired at least in non-obese model of insulin resistance, hereditary hypertriglyceridemic rats. The difference is accentuated after short-term high sucrose feeding. While in controls adrenaline increased glucose incorporation into glycerol of triglyceride molecule by $70 \%$ and FFA reesterifi-cation by $200 \%$, it had no effect in HHTg rats. In consequence, the greater portion of FFAs released by lipolysis is exported from adipose tissue into the medium compared with controls due to the lower glucose 


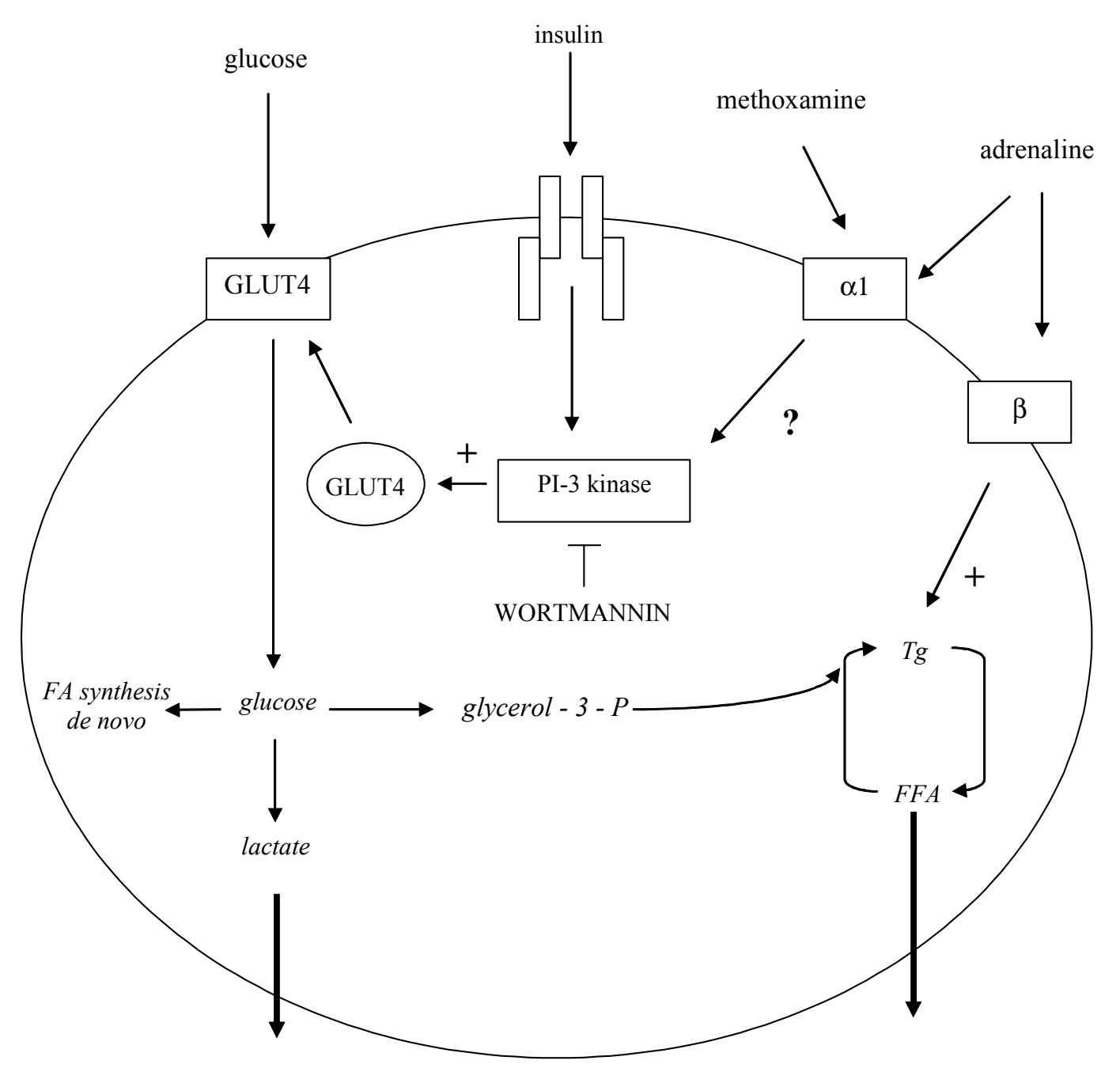

Fig. 2. The proposed mechanisms of adrenaline-stimulated glucose transport into adipocytes. The stimulation of $\beta$-adrenergic receptors activates the hydrolysis of intracellular triglycerides $(\mathrm{Tg})$ and FFA production. Part of the released FFA is exported from adipose tissue but part of them, because of the existence continuous Tg/FFA cycle, is reesterified in the tissue. In consequence, the intracellular need of glucose for FFA reesterification increases. This process is dependent on PI-3 kinase as wortmannin significantly decreased the esterification of glucose and increased the FFA release from the tissue, probably as a result of lower glucose availability. The specific stimulation of $\alpha_{1}$-adrenoreceptors by methoxamine does not increase the lipolysis but tend to increase the glucose utilization for fatty acid synthesis de novo. Adrenaline activates both types of receptors concomitantly and the glucose transported into cell after the $\alpha_{1}$ receptor activation may provide some surplus glucose for reesterification of FFA derived from adrenaline-stimulated lipolysis.

availability for FFA esterification in the situation of adrenaline-stimulated lipolysis.

Faintrenie and Geloen (1998) reported that selective stimulation of both $\alpha$ (by phenylephrine) and $\beta$ adrenergic receptors (by propranolol) increased glucose uptake into adipocytes. $\alpha$ and $\beta$ adrenoceptors are coupled with different intracellular effectors systems and therefore it is probable that stimulating effect of adrenaline on glucose utilization is mediated by more than one mechanism. Cheng et al. (2000), who employed the specific $\alpha_{1}$-adrenoceptor agonist, identified the specific role of these receptors in glucose uptake. They found that transport of glucose after specific stimulation of $\alpha_{1}$-adrenoceptors is associated with GLUT4 translocation to the plasma membrane but the mechanism of this process remains to be identified.

Our experiment in normal rats showed that adrenaline, beside its main function, which is the stimulation of lipolysis and increase of NEFA production, concomitantly activates the glucose utilization what leads to the rendering a part of the released fatty acids in adipose tissue by their reesterification. Our experiments employing concomitantly the adrenaline and PI-3 kinase inhibitor wortmannin showed that the inhibition of glucose entry into adipocytes led to the significant increase of adrenaline-stimulated FFA release and 
provided evidence supporting the important role of reesterification for final FFA release from adipose tissue in fasting animals (Table 1, Cahová, unpublished results).

Adrenaline realizes its effect on glucose utilization probably preferentially via $\beta$-adrenoceptor stimulation which leads to the increased NEFA production and consequently to the increase of intracellular need for glucose for their esterification. Nevertheless, the stimulation of $\alpha_{1}$-adrenoceptors may also contribute to the increased glucose supply to the cell. A possible mechanism is proposed in Figure 2.

\section{Conclusions}

The important role of fatty acids in the development of insulin resistance is now generally accepted. Nevertheless, the exact mechanism how fatty acids contribute to the establishment of insulin-resistant phenotype of skeletal muscle is still not completely elucidated. There is now growing evidence that the original theory (Randle or glucose-fatty acid cycle) supposing that the decreased glucose uptake in muscle is a result of increased fatty acid oxidation and suppressed glucose oxidation, cannot completely explain all experimental data. It seems that fatty acid oxidation in type 2 diabetes is decreased and the oxidation of glucose is elevated under the conditions of hyperglycemia and hyperinsulinemia. The increased oxidation of glucose leads to the rise of intracellular malonyl CoA content which is a potent inhibitor of CPT I and thus prevents the entry of fatty acids to mitochondrial oxidation. The theory of "lipotoxicity" explains the effect of fatty acids on muscle cells via the accumulation of lipid metabolism intermediates (LC-AcCoA, DAG, ceramides) in the cytoplasm. These compounds interfere with insulin signaling cascade what results in a decrease of glucose transport into tissues. The impaired uptake of glucose by tissues increases plasma glucose concentration leading to further insulin secretion and hyperinsulinemia. It starts the vicious cycle when the normal regulation of the energy substrate metabolism is disturbed and the changes at the level of substrate competition, enzyme regulation, intracellular signaling and/or gene transcription develop. One of the manifestations of this situation is "metabolic inflexibility", which is defined as an impaired ability to switch easily between glucose and fat oxidation according to the metabolic needs of the organism.

In spite of the fact that the insulin resistance manifests itself mostly in skeletal muscle, there is a lot of evidence indicating the important role of adipose tissue in the pathophysiology of insulin resistance. The experiments, in which specific manipulation in adipose tissue (e.g. fat-specific GLUT4 knock-out) induced whole body insulin resistance, indicate that insulin resistance may be initiated in one tissue and development of insulin resistance in other tissues follows. Among other mechanisms, the adipose tissue may contribute to the development of insulin resistance by impaired buffering of fatty acid fluxes not only in postprandial period but also during fasting. In consequence the non-adipose tissues are exposed to excessive fluxes of lipid fuels, which may lead to the impairment of normal regulation mechanisms in these tissues.

\section{Acknowledgements}

This work was supported by grant no. NR/7888-3 and no. NR/8495 from IGA of the Ministry of Health, Czech Republic.

\section{References}

ABEL ED, PERONI O, KIM JK, KIM YB, BOSS O, HADRO E, MINNEMANN T, SHULMAN G, KAHN BB: Adipose selective targeting of GLUT4 gene impairs insulin action in muscle and liver. Nature 409: 729-733, 2001.

AHIMA R, FLIER JS: Adipose tissue as an endocrine organ. Trends Endocrinol Metab 11: 327-332, 2000.

ANDRES R, CADER G, ZIERLER K: The quantitatively minor role of carbohydrate in oxidative metabolism by skeletal muscle in intact man in the basal state measurement of oxygen and glucose uptake and carbon dioxide production in the forearm. $J$ Clin Invest 35: 671-682, 1956.

BAVENHOLM P, PIGON JG, SAHA AK, RUDERMAN NB, FENDIC S: Fatty acid oxidation in humans is regulated by malonyl CoA in muscle. Diabetologia 41 (Suppl 1): A25, 1998.

BEVILACQUA S, BUZZIGOLI G, BONADONNA R, BONI C, CIOCIARO D, MACCARI F, GIORICO MA, FERANNINI E: Acute elevation of free fatty acid levels leads to hepatic insulin resistance in obese subjects. Metab Clin Exp 36: 502-506, 1987. 
BLAAK EE, WAGENMAKERS AJ, GLATZ JF, WOLFFENBUTTEL BH, KEMERINK GJ, LANGENBERG CJ, HEIDENDAL GA, SARIS WH: Plasma FFA utilization and fatty acid binding protein content are diminished in type 2 diabetic muscle. Am J Physiol 279: E146-E154, 2000.

BODEN G: Role of fatty acids in the pathogenesis of insulin resistance and NIDDM. Diabetes 46: 3-10, 1997.

BODEN G, JADALI F, WHITE J, LIANG Y, MOZZOLI M, CHEN X, COLEMAN E, SMITH C: Effect of fat on insulin-stimulated carbohydrate metabolism in normal men. J Clin Invest 88: 960-966, 1991.

BONADONNA RC, ZYCH K, BONI C, FERANNINI E, DEFRONZO RA: Time dependence of the interaction between lipid and glucose in humans. Am J Physiol 257: E49-E56, 1989.

CAHOVÁ M, VAVŘíNKOVÁ H, MESCHISVILI E, KAZDOVÁ L: The relationship between the impaired function of the adipose tissue and elevated levels of non-esterified fatty acids in hereditary hypertriglyceridemic rats. Aterosklerosa ISBN 80-239-3523-2, Praha, 2004a, pp 25-30.

CAHOVÁ M, VAVŘíNKOVÁ H, MESCHISVILI E, MARKOVÁ I, KAZDOVÁ L: The impaired response of nonobese hereditary hypertriglyceridemic rats to glucose load is associated with low glucose storage in energy reserves. Exp Clin Endocrinol Diabetes 11: 549-555, $2004 \mathrm{~b}$.

CARROL JE, VILLADIEGO A, MORSE DP: Fatty acid oxidation intermediates and the effect of fasting on oxidation in red and white skeletal muscle. Muscle Nerve 6: 367-373, 1983.

CARVALHO E, ELIASSON B, WESSLAU C, SMITH U: Impaired phosphorylation and insulin stimulated translocation to the plasma membrane of protein kinase B/Akt in adipocytes from type II diabetic subjects. Diabetologia 43: 1107-1115, 2000.

CHEN YD, GOLAY A, SWISLOCKI AL, REAVEN GM: Resistance to insulin suppression of plasma free fatty acid concentrations and insulin stimulation of glucose uptake in non-insulin dependent diabetes mellitus. $J$ Clin Endocrinol Metab 64: 17-21, 1987.

CHENG J, LIU I, YEN S, CHEN P: Role of $\alpha_{1 \mathrm{~A}}$-adrenoreceptor in the regulation of glucose uptake into white adipocyte of rats in vitro. Auton Neurosci 84: 140-146, 2000.

CHICCO A, BERNAL C, SORIA A, GIANGROSSI G, LOMBARDO Y: Dietary effects of partial or total substitution of sucrose for starch on glucose and lipid metabolism in dyslipidemic rats. Nutr Res 19: 281-293, 1999.

CIANFLONE K, XIA Z, CHEN LY: Critical review of acylation-stimulating protein physiology in humans and rodents. Biochim Biophys Acta 1609: 127-143, 2003.

COPPACK SW, EVANS RD, FISHER RM, FRAYN KN, GIBBONS GF, HUMPHREYS SM, KIRK ML, POTTS JL, HOCKADAY TD: Adipose tissue metabolism in obesity: lipase action in vivo before and after a mixed meal. Metabolism 41: 264-272, 1992.

CORTEZ MY, TORGAN CE, BROZINICK JT, MILLER RH, IVY JL: Effects of pyruvate and dihydroxyacetone consumption on the growth and metabolic state of obese Zucker rats. Am J Clin Nutr 53: 847-853, 1991.

DEFRONZO RA, BONADONNA RC, FERRANNINI E: Pathogenesis of NIDDM. A balanced overview. Diabetes Care 15: 318-368, 1992.

DYCK DJ, STEINBERG G, BONEN A: Insulin increases FA uptake and esterification but reduces lipid utilization in isolated contracting muscle. Am J Physiol 281: E600-E607, 2001.

FAERGEMAN N, KNUDSEN J: Role of long-chain fatty acyl CoA esters in the regulation of metabolism and cell signaling. Biochem J 323: 1-12, 1997.

FAINTRENIE G, GELOEN A: Alpha-1 adrenergic stimulation of glucose uptake in rat white adipocytes. J Pharmacol Exp Ther 286: 607-610, 1998.

FASSHAUER M, PASCHKE R: Regulation of adipocytokines and insulin resistance. Diabetologia 46: 1594-1603, 2003.

FELLEY CP, FELLEY EM, VAN MELLE GD, FRASCAROLO P, JEQUIER E, FELBER JP: Impairment of glucose disposal by infusion of triglycerid in humans: role of glycemia. Am J Physiol 256: E747-E752, 1989.

FRAYN KN: Non-esterified fatty acid metabolism and postprandial lipaemia. Atherosclerosis 141 (Suppl 1): S41-S46, 1998.

FRAYN KN: Adipose tissue as a buffer for daily lipid flux. Diabetologia 45: 1201-1210, 2002. 
FRAYN KN, SHADID S, HAMLANI R, HUMPHREYS SM, CLARK ML, FIELDING BA, BOLAND O, COPPACK SW: Regulation of fatty acid movement in human adipose tissue in the postabsorptive-to-postprandial transition. Am J Physiol 266: E308-E317, 1994.

FRAYN KN, HUMPHREYS SM, COPPACK SW: Net carbon flux across subcutaneous adipose tissue after a standard meal in normal weight and insulin resistant obese subjects. Int J Obes Relat Metab Disord 20: 795-800, 1996.

GARVEY WT, MAIANU L, HANCOCK JA, GOLICHOWSKI AM, BARON A: Gene expression of GLUT4 in skeletal muscle from insulin resistant patients with obesity, IGT, GDM and NIDDM. Diabetes 41: 465-475, 1992.

GROOP LC, BONADONNA RC, DELPRATO S, RATHEISER K, ZYCK K, FERRANNINI E, DEFRONZO RA: Glucose and free fatty acid metabolism in non-insulin-dependent diabetes mellitus. Evidence for multiple sites of insulin resistance. J Clin Invest 84: 205-213, 1989.

HANSEN I, TSALIKIAN E, BEAUFRERE B, GERICH J, HAYMOND M, RIZZA R: Insulin resistance in acromegaly: defects in both hepatic and extrahepatic insulin action. Am J Physiol 250: E269-E273, 1986.

HEGARTY B, FURLER S, YE J, COONEY G, KRAEGEN EW: The role of intramuscular lipid in insulin resistance. Acta Physiol Scand 178: 373-383, 2003.

HOTAMISLIGIL GS: Molecular mechanisms of insulin resistance and the role of adipocytes. Int J Obes Relat Metab Disord 24 (Suppl 4): S23-S27, 2000.

KAHN BB: Type 2 diabetes: when insulin secretion fails to compensate for insulin resistance. Cell 92: 593-596, 1998.

KAHN BB, FLIER JS: Obesity and insulin resistance. J Clin Invest 106: 473-481, 2000.

KELLEY DE: Skeletal muscle fat oxidation: timing and flexibility are everything. J Clin Invest 115: 1699-1702, 2005.

KELLEY DE, MANDARINO LJ: Hyperglycemia normalizes insulin-stimulated skeletal muscle glucose oxidation and storage in non-insulin dependent diabetes mellitus. J Clin Invest 86: 1999-2007, 1990.

KELLEY DE, MANDARINO LJ: Fuel selection in human skeletal muscle in insulin resistance: a reexamination. Diabetes 49: 677-683, 2000.

KELLEY DE, REILLY J, VENEMAN T, MANDARINO LJ: Effect of insulin on skeletal muscle glucose storage, oxidation and glycolysis in humans. Am J Physiol 258: E923-E929, 1990.

KELLEY DE, MOKAN M, SIMONEAU JA, MANDARINO LJ: Interaction between glucose and free fatty acid metabolism in human skeletal muscle. J Clin Invest 92: 91-98, 1993.

KIM JK, MICHAEL MD, PREVIS SF, PERONI OD, MAUVAIS-JARVIS F, NESCHEN S, KAHN BB, KAHN CR, SHULMAN GI: Redistribution of substrates to adipose tissues promotes obesity in mice with selective insulin resistance in muscle. J Clin Invest 105: 1791-1797, 2000.

KRAEGEN EW, COONEY GJ, YE J, THOMPSON A: Triglycerides, fatty acids and insulin resistancehyperinsulinemia. Exp Clin Endocrinol Diabetes 109: S516-S526, 2001.

LAYBUTT D, SCHMITZ-PFEIFER S, RUDERMAN N, CHISHOLM D, BIDEN T, KRAEGEN E: Activation of protein kinase $\mathrm{C}$-epsilon may contribute to muscle insulin resistance induced by lipid accumulation during chronic glucose infusion in rats. Diabetes 46: 241A, 1997.

LEWIS GF, CARPENTIER A, ADELI K, GIACCA A: Disordered fat storage and mobilisation in the pathogenesis of insulin resistance and type 2 diabetes. Endocr Rev 23: 201-229, 2002.

LONDOS C, SZTALRYD C, TANSEY JT, KIMMEL AR: Role of PAT proteins in lipid metabolism. Biochimie 87: 45-49, 2005.

MASLOWSKA M, SCANTLEBURY T, GERMINARIO R, CIANFLONE K: Acute in vitro production of acylation stimulating protein in differentiated human adipocytes. J Lipid Res 38: 1-11, 1997.

MATTISON R, JENSEN M: The adipocyte as an endocrine cell. Curr Opin Endocrinol Diabetes 10: 317-321, 2003.

MCGARRY JD, MILLS S, LONG C, FOSTER D: Observations on the affinity for carnitine, and malonyl-CoA sensitivity, of carnitin palmitoyltransferase I in animal and human tissues. Demonstration of the presence of malonyl CoA in non-hepatic tissues of the rat. Biochem J 214: 21-28, 1983.

MOSINGER B: Control Mechanisms of Lipid Mobilization from Adipose Tissue. Academia, Prague, 1968.

OAKES ND, BELL KS, FURLER SM, CAMILLERI S, SAHA AK, RUDERMAN NB, CHISHOLM DJ, KRAEGEN EW: Diet-induced muscle insulin resistance in rats is ameliorated by acute dietary lipid withdrawal or a single 
bout of exercise: parallel relationship between insulin stimulation of glucose uptake and suppression of longchain fatty acyl-CoA. Diabetes 46: 2022-2028, 1997a.

OAKES ND, CAMILLERI S, FURLER SM, CHISHOLM DJ, KRAEGEN EW: The insulin sensitizer, BRL 49653, reduces systemic fatty acid supply and utilization and tissue lipid availability in the rat. Metabolism 46: 935942, 1997b.

ONG J, KERN P: Effect of feeding and obesity on lipoprotein lipase activity, immunoreactive protein and messenger RNA levels in human adipose tissue. $J$ Clin Invest 84: 305-311, 1989.

PERDOMO G, COMMERFORD R, RICHARD A, ADAMS S, CORKEY B, O'DOHERTY R, BROWN N: Increased beta-oxidation in muscle cells enhances insulin-stimulated glucose metabolism and protects against fatty acidinduced insulin resistance despite intramyocellular lipid accumulation. J Biol Chem 279: 27177-27186, 2004.

PETERSEN KF, HENDLER R, PRICE T, PERSEGHIN G, ROTHMAN DL, HELD N, AMATRUDA JM, SHULMAN GI: ${ }^{13} \mathrm{C}^{\beta 1} \mathrm{P}$ NMR studies on the mechanism of insulin resistance in obesity. Diabetes 47: 381-386, 1998.

PITTAS A, NANDINI A, GREENBERG A: Adipocytokines and insulin resistance. J Clin Endocrinol Metab 89: 447452, 2004.

POYNTEN A, SENG KHEE GAN, KRIKETOS A, O'SULLIVAN A, KELLY J, ELLIS B, CHISHOLM D, CAMPBELL L: Nicotinic acid-induced insulin resistance is related to increased circulating fatty acids and fat oxidation but not muscle lipid content. Metabolism 52: 699-704, 2003.

RANDLE PJ, GARLAND P, HALES C, NEWSHOLME E: The glucose-fatty acid cycle: its role in insulin sensitivity and the metabolic disturbances of diabetes mellitus. Lancet 13: 786-789, 1963.

REAVEN GM, LITHELL H, LANDSBERG L: Hypertension and associated metabolic abnormalities - the role of insulin resistance and symphatoadrenal system. N Engl J Med 334: 374-381, 1996.

RIZZA RA, MANDARINO LJ, GERICH JE: Effects of growth hormone on insulin action in man. Mechanism of insulin resistance, impaired suppression of glucose production, and impaired stimulation of glucose utilization. Diabetes 31: 663-669, 1982.

RODEN M, PRICE T, PERSEGHIN G, PETERSEN K, ROTHMAN D, CLINE G, SHULMAN GI: Mechanisms of free fatty acid - induced insulin resistance in humans. J Clin Invest 97: 2859-2865, 1996.

RONDINONE CM, WANG LM, LONNROTH P, WESSLAU C, PIERCE JH, SMITH U: Insulin receptor substrate (IRS) 1 is reduced and IRS 2 is the main docking protein for phosphatidylinositol kinase 3 in adipocytes from subjects with non-insulin dependent diabetes mellitus. Proc Natl Acad Sci USA 94: 4171-4175, 1997.

ROTHMAN DL, SHULMAN RG, SHULMAN GI: ${ }^{31} \mathrm{P}$ nuclear magnetic resonance measurements of muscle glucose-6phophate: evidence for reduced insulin-dependent muscle glucose transport or phosphorylation activity in noninsulin dependent diabetes mellitus. J Clin Invest 89: 1069-1075, 1992.

ROTHMAN DL, MAGNUSSON I, CLINE G, GERARD D, KAHN CR, SHULMAN RG, SHULMAN GI: Decreased muscle glucose transport/phosphorylation is an early defect in the pathogenesis of non-insulin dependent diabetes mellitus. Proc Natl Acad Sci USA 92: 983-987, 1995.

RUDERMAN N, SAHA AK, VAVAS D, WITTERS A: Malonyl-CoA, fuel sensing and insulin resistance. Am $J$ Physiol 276: E1-E18, 1999.

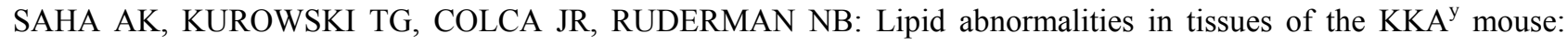
effects of pioglitazone on malonyl CoA and diacylglycerol. Am J Physiol 267: E95-E101, 1994.

SAHA AK, KUROWSKI TG, RUDERMAN NB: A malonyl-CoA fuel-sensing mechanism in muscle: effects of insulin, glucose and denervation. Am J Physiol 269: E283-E289, 1995.

SAHA AK, VAVVAS D, LAYBUTT D, CHISHOLM D, KRAEGEN EW, RUDERMAN NB: Increases in cytosolic citrate regulate malonyl CoA levels in insulin resistant muscles in vivo. Diabetes 46: 235A, 1997.

SALEH J, SUMMERS L, CIANFLONE K, FIELDING, B, SNIDERMAN A, FRAYN KN: Coordinated release of acylation stimulating protein (ASP) and triacylglycerol clearance by human adipose tissue in vivo in the postprandial period. J Lipid Res 39: 884-891, 1998.

SCHALCH DS, KIPNIS DM: Abnormalities in carbohydrate tolerance associated with elevated plasma non-esterified fatty acids. $J$ Clin Invest 44: 2010-2020, 1965. 
SHAFRIR E, RAZ I: Diabetes: mellitus or lipids? Diabetologia 46: 433-440, 2003.

SHULMAN GI: Cellular mechanisms of insulin resistance. J Clin Invest 106: 171-176, 2000.

SIDOSSIS LS, STUART CH, SHULMAN GI, LOPASCHUK GD, WOLFE RR: Glucose plus insulin regulate fat oxidation by controlling the rate of fatty acid entry into mitochondria. $J$ Clin Invest 98: 2244-2250, 1996.

SMITH U: Impaired (,diabetic") insulin signaling and action occur in fat cell long before glucose intolerance - is insulin resistance initiated in adipose tissue? Int J Obes Relat Metab Disord 26: 897-904, 2002.

STORLIEN L, OAKES N, KELLEY DE: Metabolic flexibility. Proc Nutr Soc 63: 363-368, 2004.

TANSEY JT, SZTALRYD C, GRUIA-GRAY J, ROUSH DL, ZEE JV, GAVRILOVA O, REITMAN ML, DENG CX, LI C, KIMMEL AR, LONDOS C: Perilipin ablation results in a lean mouse with aberrant adipocyte lipolysis, enhanced leptin production, and resistance to diet-induced obesity. Proc Natl Acad Sci USA 98: 6494-6499, 2001.

THIEBAUD D, DEFRONZO RA, JACOT E, GOLAY A, ACHESON K, MEADER E, JEQUIER E, FELBER J: Effect of long chain triglyceride infusion on glucose metabolism in man. Metab Clin Exp 31: 1128-1136, 1982.

THOMPSON AL, COONEY GJ: Acyl-CoA inhibition of hexokinase in rat and human skeletal muscle is a potential mechanism of lipid-induced insulin resistance. Diabetes 49: 1761-1765, 2000.

TORGAN CE, BROZINICK JT, WILLEMS ME, IVY JL: Substrate utilization during acute exercise in obese Zucker rats. J Appl Physiol 69: 1987-1991, 1990.

UKROPCOVA B, McNEIL M, SEREDA O, DeJONGE L, XIE H, BRAY GA, SMITH SR: Dynamic changes in fat oxidation in human primary myocytes mirror metabolite characteristics of the donor. J Clin Invest 115: 19341941, 2005.

WARD AM, FALL C, STEIN C: Cortisol and the metabolic syndrome in South Asians. Clin Endocrinol 58: 500-505, 2003.

WOLFE BM, KLEIN S, PETERS EJ, SCHMIDT BF, WOLFE RR: Effects of elevated free fatty acids on glucose oxidation in normal humans. Metab Clin Exp 37: 323-329, 1988.

WOLFE RR, PETERS EJ: Lipolytic response to glucose infusion in human subjects. Am J Physiol 252: E218-E223, 1987.

ZIERATH JR, GALUSKA D, NOLTE L, THORNE A, KRISTENSEN J, WALLBERG-HENRIKSSON H: Effects of glycemia on glucose transport in isolated skeletal muscle in patients with NIDDM: in vitro reversal of muscular insulin resistance. Diabetologia 37: 270-277, 1994.

ZIERATH JR, HE L, GUMA A, WAHLSTROM E, KLIP A, WALLBERG-HENRIKSSON H: Insulin action on glucose transport and plasma membrane GLUT4 content in skeletal muscle from patients with NIDDM. Diabetologia 39: 1180-1189, 1996.

\section{Reprint requests}

Monika Cahová, OMD CEM, Institute for Clinical and Experimental Medicine, Vídeňská 1958, 14200 Prague 4, Czech Republic.E-mail: moca@medicon.cz 